\title{
SPECTRAL PROPERTIES OF AN INDOTRICARBOCYANINE DYE UPON COMPLEXATION BY DETONATION NANODIAMONDS AND BLOOD SERUM PROTEINS
}

\author{
N. V. Belko, ${ }^{\text {a,b* }}$ M. P. Samtsov, ${ }^{\text {a G. A. Gusakov, }}$, \\ I. I. Khludeev, ${ }^{\text {c }}$ A. P. Lugovski, ${ }^{\text {a }}$ \\ and A. A. Lugovski ${ }^{\text {d }}$
}

Spectral properties of an indotricarbocyanine dye upon complexation with nanodiamonds in aqueous solutions were studied. Complexation was accompanied by disappearance of the $H^{*}$-aggregate absorption band at $514 \mathrm{~nm}$ and a bathochromic shift of long-wavelength absorption maxima from 706 to $718 \mathrm{~nm}$. The dye emission spectrum was almost unchanged. The fluorescence excitation peak shifted from 706 to $710 \mathrm{~nm}$. The dye carboxyl groups played an important role in the complexation of the dye to nanodiamonds based on an analysis of the IR absorption spectra. The complexes broke down and the dye molecules bonded to serum proteins in the presence of human blood serum. This was confirmed by significant increases in the fluorescence lifetime and anisotropy. The obtained complexes could be used as a basis for fluorescent biosensors.

Keywords: cyanine dyes, nanodiamonds, blood serum, complexation, absorption spectroscopy, fluorescence spectroscopy.

Introduction. Detonation nanodiamonds (DNDs) are marginally toxic, stable, chemically inert, and biocompatible nanomaterials [1-8] with a highly active surface [9]. Attempts have been made to use DNDs in medicine, e.g., to deliver drugs and to image biological processes [3, 8, 10-22].

Complexation of nanodiamonds and organic dyes that have the necessary spectral and luminescent properties is a possible route to development of fluorescent biological probes. For example, cyanine (polymethine) dyes are widely used in science and technology $[23,24]$ and have several advantages. Absorption and emission bands of cyanine dyes located in the spectral transparency range of biological tissues (700-900 nm) is the most important advantage enabling their use in biomedicine $[25,26]$. However, many compounds of this class are poorly soluble in water [23, 27-34]. Thus, substituents that make the compounds hydrophilic are introduced [33, 35-37] or various conjugates are constructed [34, 38] to provide biocompatible structures. DNDs can be used to immobilize various biologically active compounds via adsorption or covalent bonding of the molecules [16, 39]. The capability of DNDs for targeted delivery of organic molecules was demonstrated in vivo $[8,16,20,21]$. The role of DNDs is not limited to immobilization of organic molecules. They can also enhance and expand the spectrum of action of several drugs when administered as conjugates with DNDs [17, 40].

The goal of the present work was to study the spectral and luminescent characteristics of an indotricarbocyanine dye upon reaction with DNDs and the behavior of such complexes in a model biological medium containing human blood serum. The dye was chosen because it had been used earlier as an effective photosensitizer for photodynamic therapy [41].

Experimental. The indotricarbocyanine dye

\footnotetext{
* To whom correspondence should be addressed.
}

${ }^{a}$ A. N. Sevchenko Institute of Applied Physical Problems, Belarusian State University, Minsk, 220045, Belarus; email: nikita.belko@gmail.com; ${ }^{b}$ Belarusian State University, Minsk, 220030, Belarus; ${ }^{\mathrm{c}}$ Belarusian State University of Informatics and Radioelectronics, Minsk, 220013, Belarus; ${ }^{\mathrm{d}}$ Belarusian State University, Republican Center for Human Problems, Minsk, 220045, Belarus. Translated from Zhurnal Prikladnoi Spektroskopii, Vol. 87, No. 3, pp. 368-377, MayJune, 2020. Original article submitted February 5, 2020. 


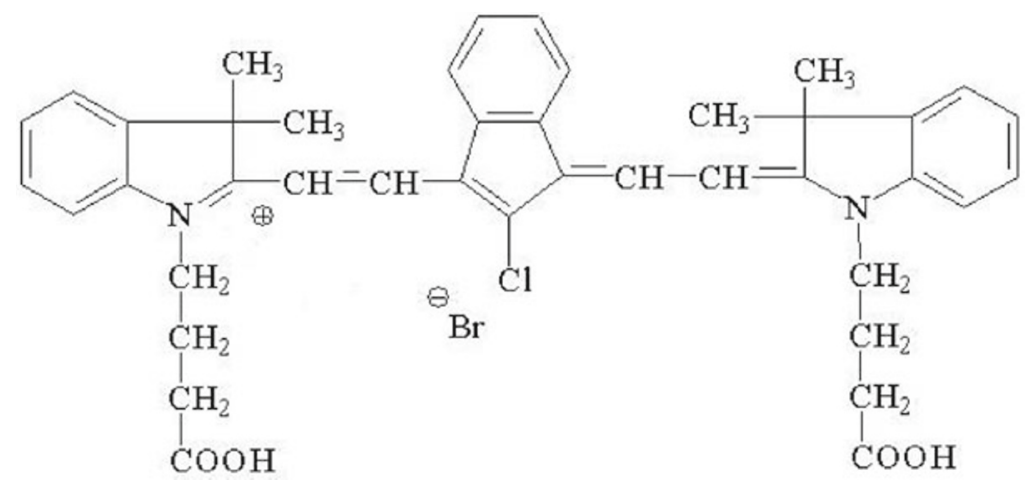

was very soluble in organic solvents but it was also hydrophobic. Aqueous solutions of the dye were prepared by adding a stock solution of the dye in $\mathrm{EtOH}$ to $\mathrm{H}_{2} \mathrm{O}$. The $\mathrm{EtOH}$ concentration in the aqueous solutions was 5 vol.\%. After the dye absorption spectrum in the aqueous solution stabilized ( $\sim 100 \mathrm{~min}$ after preparation) [42], the solution was mixed with an aqueous suspension of DNDs in a 1:1 ratio.

The studies used DNDs UDA-GO-SP (ZAO Sinta, Belarus). The starting powder was annealed in vacuo $\left(10^{-2} \mathrm{~Pa}\right)$ for $1 \mathrm{~h}$ at $750^{\circ} \mathrm{C}$. The DND surface under these heat-treatment conditions contained the minimum number of functional groups and was dominated by many dangling $\mathrm{C}$ bonds stabilized by conjugated polyenes [43]. The suspension of DND powder in $\mathrm{H}_{2} \mathrm{O}$ at concentration $0.25 \mathrm{~g} / \mathrm{L}$ was prepared in an ultrasonic bath (ultrasound frequency $35 \mathrm{kHz}$; power, $60 \mathrm{~W}$ ) for $45-60 \mathrm{~min}$ at room temperature. The resulting suspension was centrifuged for $60 \mathrm{~min}$ at $1300 \mathrm{~g}$. The supernatant was separated from the precipitate and used in the experiments.

Samples for recording IR spectra were prepared by natural drying of the solutions at room temperature. Then, the samples were dried at $50^{\circ} \mathrm{C}$ for $15 \mathrm{~h}$, mixed with $\mathrm{KBr}$ powder in a 1:500 ratio, and pressed into pellets. The starting crystalline dye was also studied in $\mathrm{KBr}$ pellets. Blood serum was prepared by clotting samples from healthy donors and settling the cellular solid by centrifugation.

Absorption spectra were recorded on Solar PV 1251 or PerkinElmer Lambda 1050 spectrophotometers; IR absorption spectra, on a Bruker Vertex 70 FT-IR spectrometer. Excitation and emission spectra, fluorescence lifetimes, and anisotropy were measured using a SPEX Fluorolog fluorescence spectrometer. Fluorescence lifetimes were determined by correlation photon counting with excitation by radiation from a semiconducting laser at $\lambda=650 \mathrm{~nm}$. Dye fluorescence spectra in the presence of blood serum were measured using excitation by laser radiation with $\lambda=684 \mathrm{~nm}$ and a locally manufactured fluorescence spectrometer.

Results and Discussion. Figure 1 (curve 1) shows the optical density spectrum of the DND aqueous suspension. The shape of the spectrum on a logarithmic scale was approximated by the linear function $\log D=f(\log \lambda)$ with correlation coefficient $>0.99$. The shape of the spectrum did not change if the layer thickness of the suspension was decreased by an order of magnitude, indicating that multiple scattering was negligibly small. The linearity of the spectrum in logarithmic coordinates and the lack of multiple scattering allowed the empirical dependence of the spectrum shape on the size of the scattering particles [44] to be used to determine the sizes of the DNDs in the suspension. The size of the DNDs in suspensions at concentrations $0.2-1.0 \mathrm{~g} / \mathrm{L}$ was calculated from the optical spectra of the aqueous DND suspensions based on this dependence. The average particle diameter considering the dispersion of the DNDs was $\sim 150 \mathrm{~nm}$. The optical density of the DND suspension did not change over one month. This indicated that the particle size was stable to sedimentation during the time of the experiments. The electronic absorption spectrum of the aqueous dye solution exhibited two strong bands (curve 2). A broad band at 600-800 nm was shown to be due to a superposition of absorptions of dye monomers and dimers with maxima at 706 and $658 \mathrm{~nm}$ [42]. A narrow band at $514 \mathrm{~nm}$ was due to $\mathrm{H}^{*}$-aggregates in the solution that were nano-sized self-assemblies of dye molecules [42].

The absorption spectrum was a superposition of DND scattering and dye absorption spectra if the aqueous DND suspension and dye solution were mixed (Fig. 1, curve 3). The component due to dye absorption could be identified by subtracting the DND light-scattering spectrum from the total spectrum (curve 4). The short-wavelength portion of the spectrum acquired a shape analogous to the dye absorption spectrum in the aqueous EtOH solution as a result of this transformation. This indicated that the size of the DNDs $(\sim 150 \mathrm{~nm})$ was unchanged after adding the dye to the solution.

The dye absorption spectrum underwent significant transformations after mixing with the DND suspension. Over time, the optical density of the absorption band of $\mathrm{H}^{*}$-aggregates at $514 \mathrm{~nm}$ decreased with simultaneous increases at 660 


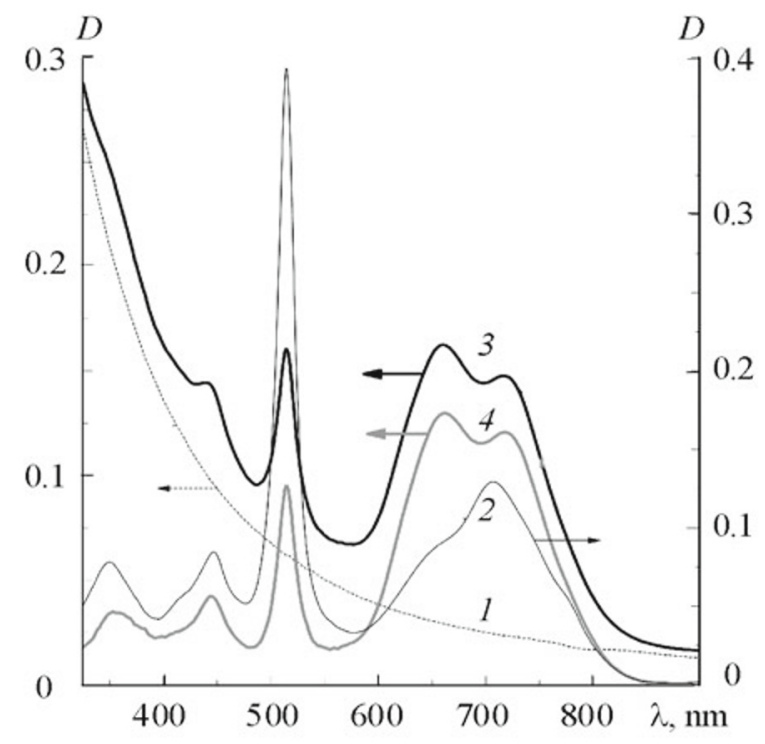

Fig. 1. Absorption spectra of an aqueous suspension of DNDs at concentration $0.5 \mathrm{~g} / \mathrm{L}(1)$; indotricarbocyanine dye in $\mathrm{H}_{2} \mathrm{O}$ at concentration $5 \mu \mathrm{M}$ and after mixing in a $1: 1$ ratio of this solution and an aqueous suspension of DNDs at concentration $0.25 \mathrm{~g} / \mathrm{L}(2,3)$; result of subtraction of spectrum 1 from spectrum 3 at dye concentration $2.5 \mu \mathrm{M}$ and DND concentration $0.25 \mathrm{~g} / \mathrm{L}$ (4); layer thickness $1 \mathrm{~cm}$.

and $718 \mathrm{~nm}$ (Fig. 2a and 2b). After $\sim 30 \mathrm{~min}$, the absorption spectrum of the suspension containing dye and DNDs ceased to change. Additional dilution of the solution with $\mathrm{H}_{2} \mathrm{O}$ after the stabilization did not change its shape (Fig. 2c). However, the contribution of the short-wavelength band at $514 \mathrm{~nm}$ in the absorption spectrum decreased upon double dilution of the starting dye solution before mixing with the DND suspension although the shapes of the bands were qualitatively essentially the same (Fig. 2d). This indicated that the transformations in the dye absorption spectrum of the dye in the presence of DNDs could not be explained by the reduced dye concentration.

The dye absorption spectrum in the presence of DNDs exhibited bands with maxima at 660 and $718 \mathrm{~nm}$ (Fig. 3, curve 1). The spectrum of the less concentrated $(0.5 \mu \mathrm{M})$ aqueous solution with only dye monomers showed a single maximum at $706 \mathrm{~nm}$ (curve 2). Dye monomers in this solution gave a fluorescence peak at $738 \mathrm{~nm}$. The fluorescence excitation spectrum of dye monomers agreed in shape and position with the dye absorption spectrum (curves 2, 4, 6). Dye fluorescence excitation and emission spectra in solutions with DNDs (curves 3 and 5) were in general similar in shape to the corresponding dye spectra in aqueous solution. The dye fluorescence excitation peak in the presence of DNDs shifted from 706 to $710 \mathrm{~nm}$ and had a larger half-width $\left(1824 \mathrm{~cm}^{-1}\right.$ as compared to $1431 \mathrm{~cm}^{-1}$ for free monomers). The emission spectrum was characterized by a somewhat stronger intensity in the long-wavelength region. The results indicated that the absorption band at $718 \mathrm{~nm}$ corresponded to dye monomers bound to DND surfaces; at $660 \mathrm{~nm}$, to absorption of dimers that did not fluoresce [42]. The fluorescence of suspensions containing DNDs and dye resulted from emission of dye monomers in $\mathrm{H}_{2} \mathrm{O}$ and in DND-dye complexes. The fluorescence anisotropy of free dye monomers in aqueous solution was $31 \pm 2 \%$; its lifetime, $0.5 \pm 0.1 \mathrm{~ns}$. These parameters had the same values within experimental uncertainty as the dye in the DND suspension. The differences in the fluorescence anisotropy and lifetime, if they existed, were less than $4 \%$ and $0.2 \mathrm{~ns}$. The results indicated that free dye monomers contributed most to the fluorescence excitation and emission spectra although their fraction in the suspension of DND-dye complexes was small according to the absorption spectra. The long-wavelength tail in the fluorescence excitation and emission spectra was characteristic of emission from monomers bound to nanodiamonds.

DND samples with parameters that were previously studied [43] were chosen for complexation with the dye because the chemical composition of DND surfaces varies depending on the treatment conditions [39, 45, 46]. The heat-treatment conditions (vacuum annealing at $750^{\circ} \mathrm{C}$ ) produced nanodiamonds with the minimum amount of surface functional groups [43]. The surface of the used DND powders were dominated by $\geq \mathrm{C}-\mathrm{O}-\mathrm{C} \leq$ groups in acid anhydrides, ethers, lactones, and epoxides [43]. The DND surface could also contain polyene fragments [47, 48]. 

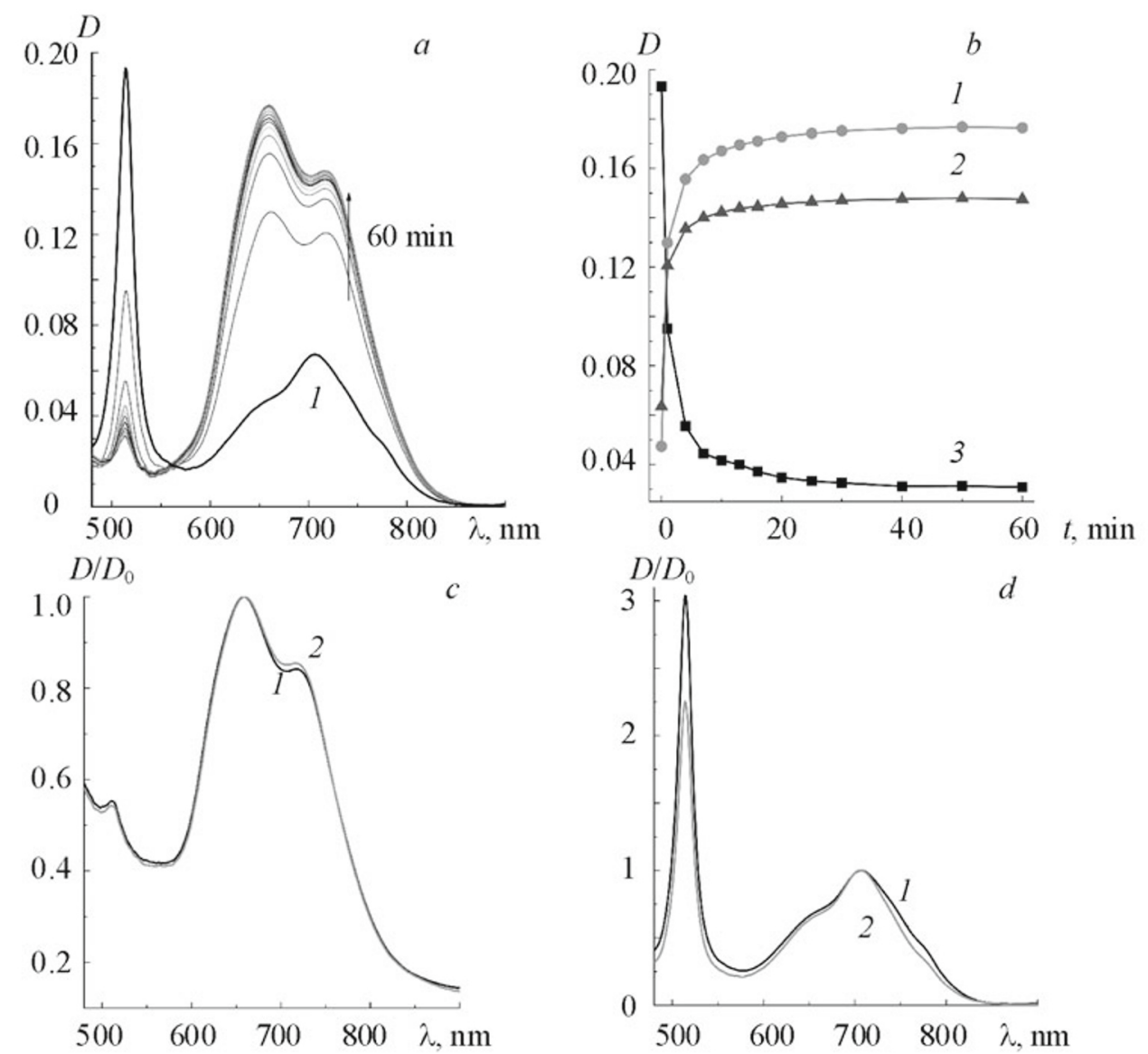

Fig. 2. Absorption spectra of dye after mixing of its aqueous solution with an aqueous suspension of DNDs in a 1:1 ratio for $60 \mathrm{~min}$ and without DNDs (1); kinetics of change of optical density at absorption peaks at 660 (1), 718 (2), and $514 \mathrm{~nm}$ (3); dye concentration $2.5 \mu \mathrm{M}$, DND concentration $0.25 \mathrm{~g} / \mathrm{L}$, layer thickness $1 \mathrm{~cm}(\mathrm{~b})$; normalized absorption spectra 60 min after mixing an aqueous solution of indotricarbocyanine dye with an aqueous suspension of DNDs in a 1:1 ratio (1) and after additional double dilution in $\mathrm{H}_{2} \mathrm{O}$ (2) (c); normalized (to $706 \mathrm{~nm}$ ) absorption spectra of starting aqueous solution of dye (1) and after dilution by $\mathrm{H}_{2} \mathrm{O}$ in a 1:1 ratio (2) (d).

H-bonds between dye molecules and suitable functional groups on the DND surfaces could form because the dye molecule contained carboxylic acids. Facets of DND particles were reported to have various electrostatic potentials, i.e., from positive to negative [21]. The studied dye was cationic. Therefore, ionic interactions could also facilitate bonding of the dye to the DNDs. The dye molecules contained an extended $\pi$-electron system of a polymethine chain and terminal aromatic groups. Hence, the dye was predisposed to dispersion forces [49] that were critical to complexation of the dye to the DNDs because the DND surface contained polyene fragments $[47,48]$.

IR absorption spectra were analyzed to establish the nature of the bonds involved in forming the DND-dye complexes. The complexes were prepared in several steps. First, starting dye was dissolved in EtOH. Second, the stock EtOH solution was diluted in water. Third, the resulting aqueous EtOH solution was mixed with an aqueous suspension of DNDs. Therefore, IR absorption spectra of the three samples were compared. Sample No. 1 was starting crystalline dye. Sample No. 2 was taken from the aqueous EtOH solution of the dye after $\mathrm{H}^{*}$-aggregation was finished (Fig. 1, curve 2). Sample No. 3 was prepared from the aqueous EtOH dye solution mixed with the DND suspension (Fig. 2a). Bands in the IR absorption spectra were assigned based on these data [50-52].

Figure 4 shows the IR absorption spectrum of the starting dye. The spectrum showed $\mathrm{C}-\mathrm{H}$ bending, $\mathrm{C}-\mathrm{C}$ skeletal, and carboxyl $\mathrm{C}-\mathrm{O}$ vibrations in the range $500-1600 \mathrm{~cm}^{-1}$. A medium intensity band for $\mathrm{C}=\mathrm{O}$ vibrations appeared at 

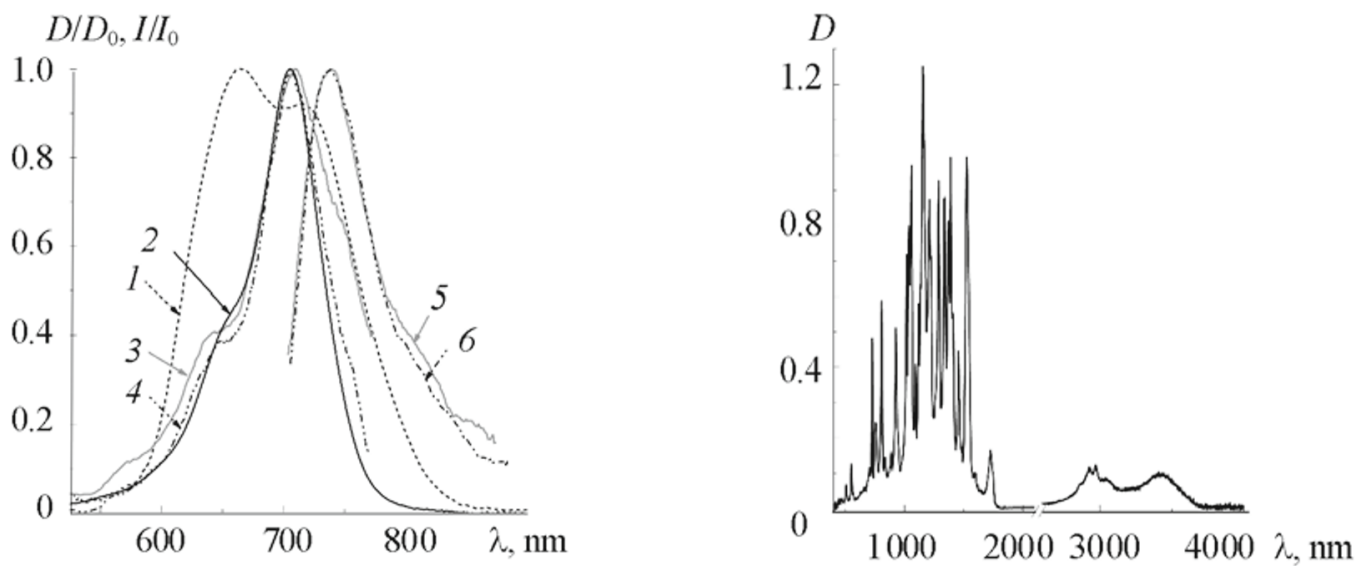

Fig. 3. Normalized absorption $(1,2)$, fluorescence excitation $\left(\lambda_{\text {rec }}=800 \mathrm{~nm}\right)(3,4)$, and fluorescence emission spectra $\left(\lambda_{\mathrm{ex}}=690 \mathrm{~nm}\right)(5,6)$ of dye in an aqueous suspension of DNDs $(1,3,5)$ and dye monomers in aqueous solution $(2,4,6)$; DND concentration $0.13 \mathrm{~g} / \mathrm{L}$, dye concentration in DND suspension $1.3 \mu \mathrm{M}$, dye concentration in aqueous solution $0.5 \mu \mathrm{M}$, layer thickness $1.0 \mathrm{~cm}$.

Fig. 4. IR absorption spectrum of starting dye.

$1700-1760 \mathrm{~cm}^{-1}$. Finally, broad bands for $-\mathrm{OH}$ stretching vibrations were observed in the range $2500-3700 \mathrm{~cm}^{-1}$ and were overlapped by $\mathrm{C}-\mathrm{H}$ stretching vibrations in the range $2800-3100 \mathrm{~cm}^{-1}$.

Absorption bands in the range $500-1550 \mathrm{~cm}^{-1}$ did not undergo substantial changes of shape and position during formation of $\mathrm{H}^{*}$-aggregates in the aqueous EtOH solution and during their destruction upon adding DNDs (samples Nos. 2 and 3). The main changes were observed in the ranges of hydroxyl and carbonyl absorptions. Therefore, spectra of the samples were compared by normalizing to the intensity of the absorption band with a maximum at $1523-1527 \mathrm{~cm}^{-1}$, which was related to skeletal vibrations of $\mathrm{C}$ atoms in the aromatic rings. Figure 5 shows the results.

Three broad bands with maxima at $\sim 3420,3000$, and $2550 \mathrm{~cm}^{-1}$ that were attributed to $\mathrm{OH}$ vibrations were observed in addition to the $\mathrm{C}-\mathrm{H}$ stretching vibrations in the range $2500-3700 \mathrm{~cm}^{-1}$ for the starting dye (Fig. 5a). The peak at $\sim 3420 \mathrm{~cm}^{-1}$ could be assigned to $-\mathrm{OH}$ vibrations in $\mathrm{H}_{2} \mathrm{O}$ (adsorbed water). The band with a maximum at $\sim 3000 \mathrm{~cm}^{-1}$ and a weak band at 2500-2700 $\mathrm{cm}^{-1}$ were due to stretching vibrations of bound -OH groups of the dye carboxylic acids. Absorption bands in the range $2500-3200 \mathrm{~cm}^{-1}$ were characteristic of carboxylic acids with strong intermolecular H-bonds between carboxylic groups $[50,51]$. The presence of H-bonds between carboxylic groups was confirmed by the shape of the carbonyl absorption band that was a doublet with maxima at 1725 and $1748 \mathrm{~cm}^{-1}$ (Fig. 5b). Splitting of carbonyl absorption bands is often observed after dimerization of carboxylic acids when dimers and monomers are present simultaneously [53, 54]. A similar effect is characteristic of crystalline polymers of carboxylic acids [54, 55].

Sample No. 2 contained dye $\mathrm{H}^{*}$-aggregates. The bands at $\sim 3000$ and $2500-2700 \mathrm{~cm}^{-1}$ disappeared in its IR spectrum (Fig. 5a), indicating that intermolecular bonds between carboxylic groups were absent. The band for adsorbed water strengthened considerably, primarily because of bound molecules $\left(3250 \mathrm{~cm}^{-1}\right)$. Also, an additional absorption band with a maximum at $1645 \mathrm{~cm}^{-1}$ appeared (Fig. $5 \mathrm{~b}$ ) and corresponded to $-\mathrm{OH}$ bending vibrations in water resulting from hydration of released carboxylic groups. The carbonyl absorption band shifted to higher frequencies from 1725 to $1735 \mathrm{~cm}^{-1}$ (Fig. 5b), indicative of weakening of the carboxylic H-bonds. Hence, the carboxylic groups were not involved in formation of dye $\mathrm{H}^{*}$-aggregates. It could be proposed that the dye molecules aggregated through van-der-Waals interactions.

The absorption band for $\mathrm{H}^{*}$-aggregates diminished and the absorption of dye dimers at $660 \mathrm{~nm}$ increased upon mixing the aqueous EtOH dye solution and the DND suspension (sample No. 3) (Fig. 2a). The weak bands at 3000 and 2500 $2700 \mathrm{~cm}^{-1}$ reappeared in the IR absorption spectra (Fig. 5a). The carbonyl absorption band experienced a low-frequency shift from 1735 to $1723 \mathrm{~cm}^{-1}$ (Fig. 5b), indicating that H-bonds formed between carboxylic groups, apparently because of dimer formation. The bands at $1550-1600 \mathrm{~cm}^{-1}$ that could be assigned to absorption of ionized carboxylic groups $\left(-\mathrm{COO}^{-}\right)$ strengthened (Fig. 5b). Intrinsic absorption of DNDs in the discussed frequency ranges of the IR absorption spectrum did not noticeably contribute (curve 4). 

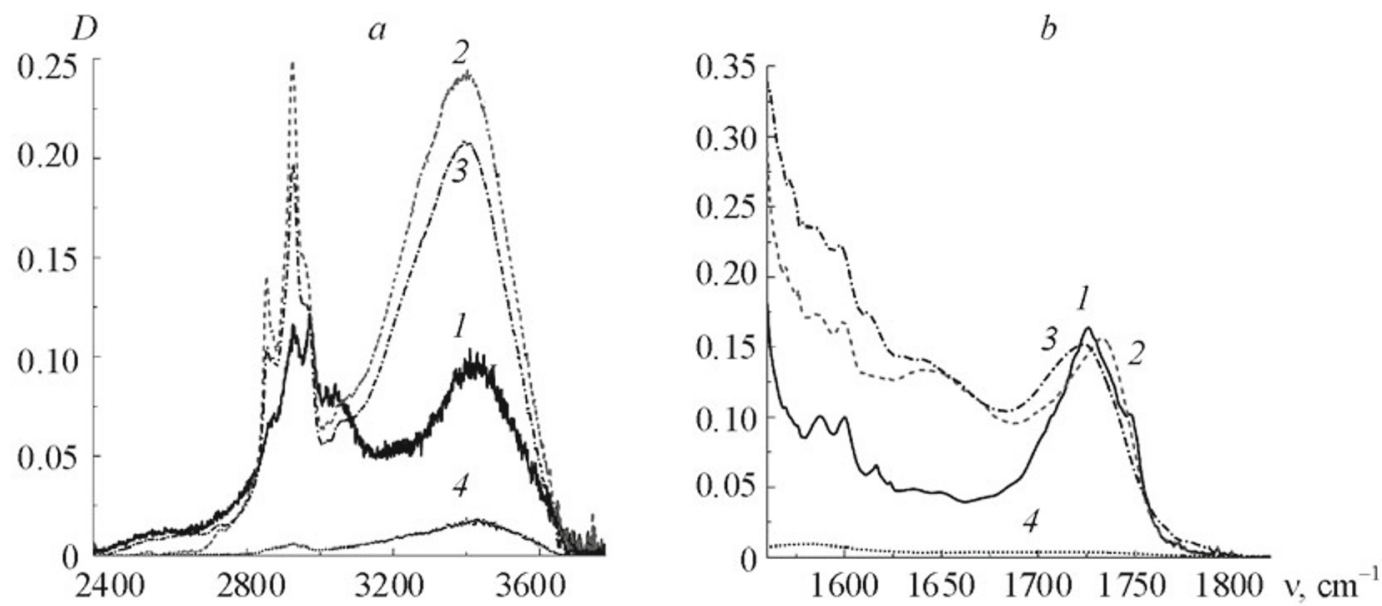

Fig. 5. IR absorption spectra of starting dye (1); sample No. 2 prepared from an aqueous EtOH solution of dye after finishing self-assembly of $\mathrm{H}^{*}$-aggregates (2); sample No. 3 prepared from an aqueous EtOH solution of dye mixed with a DND suspension (3); and DND powder (4) in the frequency ranges $2400-3500$ (a) and $1600-1800 \mathrm{~cm}^{-1}$ (b).
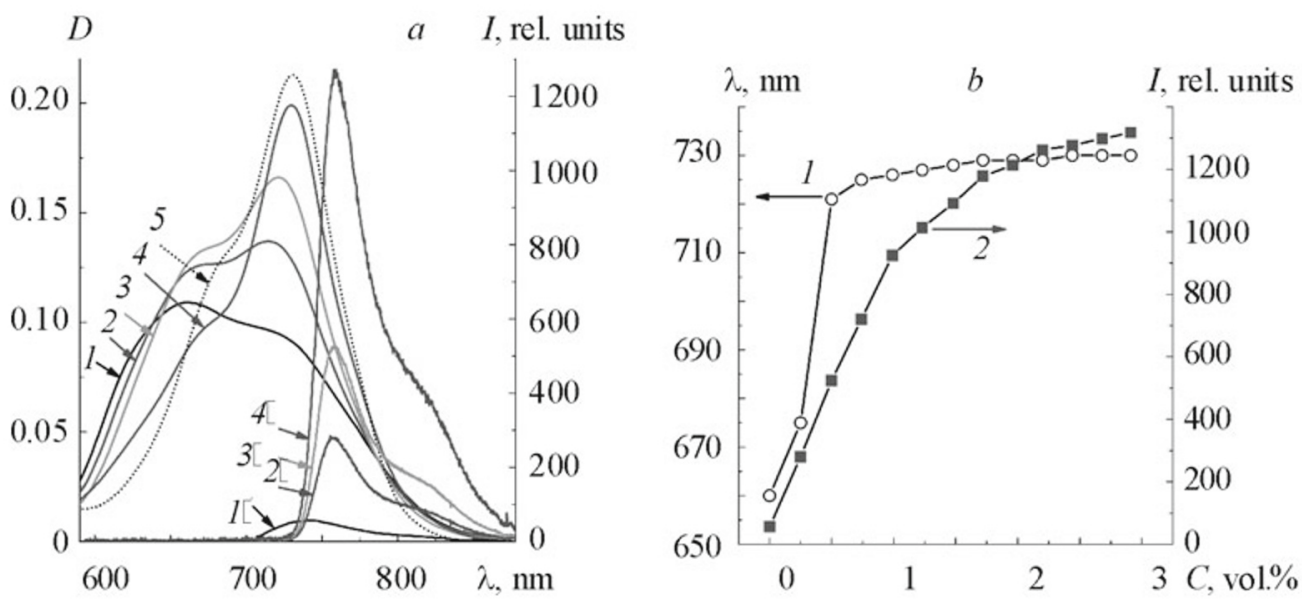

Fig. 6. Absorption (1-4) and fluorescence spectra $\left(\lambda_{\mathrm{ex}}=684 \mathrm{~nm}\right)\left(1^{\prime}-4^{\prime}\right)$ of dye in a DND suspension at blood serum concentration $0\left(1,1^{\prime}\right), 0.25\left(2,2^{\prime}\right), 0.5\left(3,3^{\prime}\right)$, and 2.2 vol.\% (4, 4'); absorption spectrum of aqueous EtOH solution of dye containing 2 vol.\% blood serum (5), at dye concentration $1 \mu \mathrm{M}$ and layer thickness $1 \mathrm{~cm}$ (a); position of absorption spectrum maximum (1) and fluorescence peak (2) as functions of blood serum concentration; dye concentration $13 \mu \mathrm{M}$, DND concentration $0.49 \mathrm{~g} / \mathrm{L}$, layer thickness $2 \mathrm{~mm}$.

It was concluded based on the above results that addition of DNDs led to deprotonation of some of the dye carboxylic groups. Then, electron density shifted and weakened the van-der-Waals interactions between the dye molecules and destroyed the $\mathrm{H}^{*}$-aggregates. Hence, the carboxylic groups in the dye molecules were responsible for the interaction with the nanodiamond surface.

Attempts were made to use DNDs for in vivo targeted drug delivery [3, 8, 10, 16, 20, 21]. The hydrophobic indotricarbocyanine dye could be administered into biological systems via immobilization on nanodiamonds. Binding of the cyanine dyes to biomolecules led to substantial changes of their spectral and luminescent properties [56-59] as compared to those in aqueous solutions. Previously, changes of the spectral properties of an indotricarbocyanine dye were studied after 
addition of human blood serum to its aqueous solutions [60]. Absorption maxima of the dye shifted from 706 to $730 \mathrm{~nm}$ as the serum concentration increased from 0 to 2 vol.\%. The dye was bonded primarily to human serum albumin (HSA). The absorption maximum at $730 \mathrm{~nm}$ corresponded to bound dye molecules [60].

The influence of blood serum on dye complexes with nanodiamonds was studied by adding to the sample aliquots of blood serum to increase its total concentration in steps of $0.25 \mathrm{vol} \%$ after the shape of the absorption spectrum of the aqueous suspension of the DND-dye complexes stabilized. The optical density increased and the maximum shifted from 660 to $730 \mathrm{~nm}$ upon increasing the blood serum concentration from 0 to 3 vol.\% in the aqueous solution containing the DND-dye complexes (Fig. 6). The fluorescence peak shifted from 738 to $756 \mathrm{~nm}$ and strengthened by $\sim 20$ times (Fig. 6b). The position of the absorption maximum reached a constant value at serum concentration $\sim 2$ vol. $\%$. The absorption spectrum approached that of the dye solution containing 2 vol.\% blood serum without DNDs (Fig. 6a, curve 5).

The initial bathochromic shift of the absorption band upon adding 0.25 vol.\% blood serum may have been related to destruction of dye dimers into monomers. The destruction of the dimers led to enhanced emission intensity because the dye monomers fluoresced, in contrast to the dimers [42]. The dye monomers bonded to biomolecules if the serum concentration was increased further. As a result, the absorption maximum continued to shift bathochromically and the fluorescence intensity increased. The significant increase of the fluorescence lifetime to $1.8 \pm 0.1 \mathrm{~ns}$ and the increase of fluorescence anisotropy to $43 \pm 2 \%$ in solutions containing 3 vol. $\%$ human blood serum indicated that the dye bonded to biomolecules. The shape change of the absorption spectrum after adding blood serum indicated that the DND-dye complexes were destroyed in the presence of biomolecules. The absorption and fluorescence spectra of the dye in the presence of human blood serum for solutions with DND-dye complexes or after adding dye from a stock solution had the same shape and position. Also, the decay time of $1.8 \pm 0.1 \mathrm{~ns}$ and fluorescence anisotropy of $43 \pm 2 \%$ agreed for both solutions. This coincidence of the spectral and luminescent properties of the dye indicated that the dye molecules in both instances were located at the same binding sites of the biological structures.

It was concluded based on the results that dye molecules were desorbed from DND surfaces after adding blood serum and converted primarily to complexes with HSA, to which they demonstrated affinity according to the literature [60]. Desorption of the dye from the DNDs in the presence of blood serum indicated that the dye bound more strongly to the blood serum components than to DNDs.

Conclusions. An indocarbocyanine dye formed complexes with DNDs in aqueous solution. The complexes had characteristic absorption maxima and shifted bathochromically relative to the spectrum of free dye monomers. Binding of the dye to DNDs led to partial fluorescence quenching. Its lifetime and anisotropy were practically unchanged. Carboxylic groups of the dye molecules played the lead role in complexation according to IR absorption spectra.

The DND-dye complexes were destroyed in the presence of human blood serum. The dye molecules bonded to serum components. The dye absorption maximum shifted bathochromically whereas the intensity, anisotropy, and fluorescence lifetime increased substantially. The results indicated that dye molecules were more strongly bound to blood serum proteins than to DNDs.

The DND-dye complexes could be considered effective fluorescent probes, the fluorescence of which was activated by binding of the dye to blood serum proteins. The fluorescence peak at $756 \mathrm{~nm}$ lay in the window of the greatest transparency of biological tissues [25,26], did not overlap the luminescence of endogenous molecules [61], and could be used for in vivo biomedical diagnosis. Infusion solutions of the hydrophobic indotricarbocyanine dye for intravenous injection could be prepared by immobilization on the surfaces of DNDs.

\section{REFERENCES}

1. A. M. Schrand, H. Huang, C. Carlson, J. J. Schlager, E. Osawa, S. M. Hussain, and L. Dai, J. Phys. Chem. B, 111, No. 1, 2-7 (2007).

2. A. M. Schrand, L. Dai, J. J. Schlager, S. M. Hussain, and E. Osawa, Diamond Relat. Mater., 16, No. 12, 2118-2123 (2007).

3. A. M. Schrand, S. A. C. Hens, and O. A. Shenderova, Crit. Rev. Solid State Mater. Sci., 34, Nos. 1-2, 18-74 (2009).

4. A. S. Barnard, Analyst, 134, No. 9, 1751-1764 (2009).

5. X. Zhang, W. Hu, J. Li, L. Tao, and Y. Wei, Toxicol. Res., 1, No. 1, $62-68$ (2012).

6. V. N. Mochalin, O. Shenderova, D. Ho, and Y. Gogotsi, Nat. Nanotech., 7, No. 1, 11-23 (2012).

7. H. B. Man and D. Ho, J. Lab. Autom., 18, No. 1, 12-18 (2013).

8. L. Lai and A. S. Barnard, J. Nanosci. Nanotech., 15, No. 2, 989-999 (2015). 
9. B. V. Spitsyn, S. A. Denisov, and N. A. Skorik, Diamond Relat. Mater., 19, Nos. 2-3, 123-127 (2010).

10. K. B. Holt, Philos. Trans. R. Soc., Ser. A, 365, No. 1861, 2845-2861 (2007).

11. K. K. Liu, M. F. Chen, P. Y. Chen, T. J. F. Lee, C. L. Cheng, C. C. Chang, Y. P. Ho, and J. I. Chao, Nanotechnology, 19, No. 20, 205102 (2008).

12. K. K. Liu, C. C. Wang, C. L. Cheng, and J. I. Chao, Biomaterials, 30, No. 26, 4249-4259 (2009).

13. T. L. Wee, Y. W. Mau, C. Y. Fang, H. L. Hsu, C. C. Han, and H. C. Chang, Diamond Relat. Mater, 18, Nos. 2-3, 567-573 (2009).

14. N. Mohan, Y. K. Tzeng, L. Yang, Y. Y. Chen, Y. Y. Hui, C. Y. Fang, and H. C. Chang, Adv. Mater., 22, No. 7, 843-847 (2010).

15. Y. Y. Hui, C. L. Cheng, and H. C. Chang, J. Phys. D: Appl. Phys., 43, No. 37.374021 (2010).

16. J. M. Say, C. van Vreden, D. J. Reilly, L. J. Brown, J. R. Rabeau, and N. J. C. King, Biophys. Rev, 3, No. 4, 171-184 (2011).

17. E. K. Chow, X. Q. Zhang, M. Chen, R. Lam, E. Robinson, H. Huang, D. Schaffer, E. Osawa, A. Goga, and D. Ho, Sci. Transl. Med., 3, No. 73, 73 ra21 (2011).

18. A. Krueger, J. Mat. Chem., 21, No. 34, 12571-12578 (2011).

19. V. Petrakova, A. Taylor, I. Kratochvilova, F. Fendrych, J. Vacik, J. Kucka, J. Stursa, P. Cigler, M. Ledvina, A. Fiserova, and P. Kneppo, Adv. Funct. Mater., 22, No. 4, 812-819 (2012).

20. R. G. Mendes, A. Bachmatiuk, B. Buchner, G. Cuniberti, and M. H. Rümmeli, J. Mater. Chem. B, 1, No. 4, 401-428 (2013).

21. D. Ho, C. H. K. Wang, and E. K. H. Chow, Sci. Adv., 1, No. 7, e1500439 (2015).

22. K. Turcheniuk and V. Mochalin, Nanotechnology, 28, No. 25, 252001 (2017).

23. A. Mishra, R. K. Behera, P. K. Behera, B. K. Mishra, and G. B. Behera, Chem. Rev., 100, No. 6, 1973-2012 (2000).

24. F. Würthner, T. E. Kaiser, and C. R. Saha-Möller, Angew. Chem., Int. Ed., 50, No. 15, 3376-3410 (2011).

25. R. R. Anderson and J. A. Parrish, J. Invest. Dermatol., 77, No. 1, 13-19 (1981).

26. P. Agostinis, K. Berg, K. A. Cengel, T. H. Foster, A. W. Girotti, S. O. Gollnick, S. M. Hahn, M. R. Hamblin, A. Juzeniene, D. Kessel, and M. Korbelik, Ca-Cancer J. Clin., 61, No. 4, 250-281 (2011).

27. S. Li, L. He, F. Xiong, Y. Li, and G. Yang, J. Phys. Chem. B, 108, No. 30, 10887-10892 (2004).

28. H. von Berlepsch, S. Kirstein, R. Hania, A. Pugzlys, and C. Böttcher, J. Phys. Chem. B, 111, No. 7, 1701-1711 (2007).

29. A. K. Chibisov, T. D. Slavnova, and Kh. Gerner, Ross. Nanotekhnol., 3, Nos. 1-2, 26-41 (2008).

30. S. Chakraborty, P. Debnath, D. Dey, D. Bhattacharjee, and S. A. Hussain, J. Photochem. Photobiol., A, 293, 57-64 (2014).

31. N. Sato, T. Fujimura, T. Shimada, T. Tani, and S. Takagi, Tetrahedron Lett., 56, No. 22, 2902-2905 (2015).

32. S. Van Der Wal, J. Kuil, A. R. P. M. Valentijn, and F. W. B. Van Leeuwen, Dyes Pigm., 132, 7-19 (2016).

33. X. Qiu, L. Xu, Y. Zhang, A. Yuan, K. Wang, X. Zhao, J. Wu, H. Guo, and Y. Hu, Mol. Pharm., 13, No. 3, 829-838 (2016).

34. S. Uthaman, A. P. Mathew, H. J. Park, B. I. Lee, H. S. Kim, K. M. Huh, and I. K. Park, Carbohydr. Polym., 181, 1-9 (2018).

35. A. A. Lugovski, M. P. Samtsov, K. N. Kaplevsky, D. Tarasau, E. S. Voropay, P. T. Petrov, and Y. P. Istomin, J. Photochem. Photobiol., A, 316, 31-36 (2016).

36. T. Lin, A. Yuan, X. Zhao, H. Lian, J. Zhuang, W. Chen, Q. Zhang, G. Liu, S. Zhang, W. Cao, and C. Zhang, Acta Biomater., 53, 427-438 (2017).

37. A. V. Sorokin, I. Y. Ropakova, R. S. Grynyov, M. M. Vilkisky, V. M. Liakh, I. A. Borovoy, S. L. Yefimova, and Y. V. Malyukin, Dyes Pigm., 152, 49-53 (2018).

38. Y. Chen, Z. Li, H. Wang, Y. Wang, H. Han, Q. Jin, and J. Ji, ACS Appl. Mater. Interfaces, 8, No. 11, 6852-6858 (2016).

39. A. Krueger and D. Lang, Adv. Funct. Mater, 22, No. 5, 890-906 (2012).

40. V. A. Lapina, S. B. Bushuk, T. A. Pavich, and A. V. Vorobei, Zh. Prikl. Spektrosk., 83, 347-353 (2016) [V. A. Lapina, S. B. Bushuk, T. A. Pavich, and A. V. Vorobey, J. Appl. Spectrosc., 83, No. 3, 344-349 (2016)].

41. E. S. Voropai, M. P. Samtsov, K. N. Kaplevskii, D. G. Mel'nikov, and L. S. Lyashenko, Izv. Ross. Akad. Nauk, Ser. Fiz., 71, No. 1, 145-149 (2007). 
42. N. V. Bel'ko, M. P. Samtsov, G. A. Gusakov, D. S. Tarasov, A. A. Lugovskii, and E. S. Voropai, Zh. Prikl. Spektrosk., 85, No. 6, 868-878 (2018) [N. V. Belko, M. P. Samtsov, G. A. Gusakov, D. S. Tarasau, A. A. Lugovski, and E. S. Voropay, J. Appl. Spectrosc., 85, No. 6, 997-1005 (2019)].

43. G. A. Gusakov, A. A. Lugovskii, A. P. Lugovskii, M. P. Samtsov, V. A. Parkhomenko, and I. I. Azarko, Zh. Prikl. Spektrosk., 87, No. 1, 33-42 (2020) [G. A. Gusakov, A. A. Lugovski, A. P. Lugovski, M. P. Samtsov, V. A. Parhomenko, and I. I. Azarko, J. Appl. Spectrosc., 87, 26-34 (2020)].

44. W. Heller, H. B. Klevens, and H. Oppenheimer, J. Chem. Phys., 14, No. 9, 566-567 (1946).

45. I. I. Kulakova, Phys. Solid State, 46, No. 4, 636-643 (2004).

46. Y. Liu, Z. Gu, J. L. Margrave, and V. N. Khabashesku, Chem. Mater., 16, No. 20, 3924-3930 (2004).

47. K. V. Reikh, Pis'ma Zh. Eksp. Teor. Fiz., 94, No. 1, 23-27 (2011).

48. A. E. Aleksenskii, A. Ya. Bul', S. V. Konyakhin, K. V. Reikh, L. V. Sharonova, and E. D. Eidel'man, Fiz. Tverd. Tela, 54, No. 3, 541-548 (2012).

49. A. H. Herz, Adv. Colloid Interface Sci., 8, No. 4, 237-298 (1977).

50. L. J. Bellamy, The Infra-Red Spectra of Complex Molecules, 2nd edn., Methuen \& Co., London (1958), 425 pp. [Russian translation, Inostr. Lit., Moscow (1963), pp. 231-232].

51. L. J. Bellamy, Advances in Infrared Group Frequencies, Methuen, London (1968) [Russian transl., Mir, Moscow (1971), pp. 287-288].

52. L. M. Ilharco and R. B. de Barros, Langmuir, 16, No. 24, 9331-9337 (2000).

53. B. G. Cox, Acids and Bases: Solvent Effects on Acid-Base Strength, Oxford University Press, Oxford (2013), pp. 44-45.

54. R. C. Millikan and K. S. Pitzer, J. Am. Chem. Soc., 80, No. 14, 3515-3521 (1958).

55. P. J. Corish and W. H. T. Davison, J. Chem. Soc., 2431-2436 (1955).

56. T. D. Slavnova, H. Gorner, and A. K. Chibisov, J. Phys. Chem. B, 111, No. 33, 10023-10031 (2007).

57. H. von Berlepsch, E. Brandenburg, B. Koksch, and C. Bottcher, Langmuir, 26, No. 13, 11452-11460 (2010).

58. K. Vus, U. Tarabara, A. Kurutos, O. Ryzhova, G. Gorbenko, V. Trusova, N. Gadjev, and T. Deligeorgiev, Mol. BioSyst., 13, No. 5, 970-980 (2017).

59. E. S. Voropay, M. P. Samtsov, and L. S. Lyashenko, Zh. Beloruss. Gos. Univ. Fiz., No 1, 28-33 (2017).

60. N. V. Bel'ko, I. I. Khludeev, V. P. Zorin, and M. P. Samtsov, Vestsi Beloruss. Gos. Pedagog. Univ., Ser. 3, No. 1, 14-20 (2018).

61. M. Monici, Biotech. Ann. Rev., 11, 227-256 (2005). 